\title{
Vision standards for driving: what ophthalmologists need to know
}

GB Rees

Eye (2015) 29, 719-720; doi:10.1038/eye.2015.38; published online 17 April 2015

\section{Driver and vehicle licensing agency}

The Driver and Vehicle Licensing Agency (DVLA) is an executive agency of the Department for Transport.

\section{Licence groups}

In Great Britain, there are 45.9 million group 1 (ordinary) licence holders eligible to drive a car and/or motorcycle, and of these 1.3 million also have group 2 (vocational) entitlement to enable them to drive a large lorry and/or bus. Higher medical standards apply to group 2 .

\section{Legal basis for the medical standards}

The legal basis of fitness to drive lies in the third EC Directive on driving licences (2006/126/ EEC), which came into effect in the United Kingdom in January 2013, the Road Traffic Act 1988 and the Motor Vehicles (driving licences) Regulations 1999 (as amended).

\section{Drivers' medical group}

Medical cases comprise around $4.3 \%$ of licence holders and are considered by the Drivers' Medical Group at DVLA. The Secretary of State for Transport, acting through DVLA, has a responsibility to ensure all licence holders are medically fit to drive.

\section{Honorary medical advisory panels}

Honorary Medical Advisory Panels consist of specialists eminent in their particular field of expertise, along with lay members. Panel members are appointed by the Secretary of State for Transport. The Vision Panel meets biannually to advise on vision standards for driving in line with the latest clinical practice, research developments and so on. The Panel also considers individual cases when requested by DVLA. The minutes of Panel meetings are available on the DVLA website. ${ }^{1}$

\section{Roles of DVLA medical advisers}

The Medical Advisers are doctors fully registered with the General Medical Council. They assess medical fitness to drive and make licensing decisions on behalf of the Secretary of State. Medical Advisers do not see and examine patients but commission medical reports as appropriate and make licensing decisions accordingly using an electronic case work system. They also represent the Secretary of State as expert witnesses in Court at both Appeal hearings and at Coroners' Courts. They have an input into policy and research and may act as secretary to one of the six expert panels that advise the Secretary of State. They also give lectures to interested parties and provide telephone and written advice to individual doctors. ${ }^{2,3}$

\section{Medical assessments of fitness to drive}

Self-declaration forms the basis of driver licensing in Great Britain. ${ }^{4}$ The Road Traffic Act requires all drivers and applicants for a driving licence to notify DVLA of any medical condition that may affect safe driving. ${ }^{5}$ Following such notification Medical Advisers may be able to make a licensing decision, but sometimes further medical information is needed.

\section{Visual acuity standards}

Group 1 entitlement requires (a) a visual acuity, with glasses or contact lenses if needed, of at least Snellen 6/12 and (b) an ability to read from a distance of $20 \mathrm{~m}$, in good light and with glasses or contact lenses if needed, a vehicle registration
Drivers' Medical Group, DVLA, Swansea, UK

Correspondence: GB Rees, Drivers' Medical Group, DVLA, Swansea SA6 7JL, UK Tel: +44 (0)1792 782337; Fax: +44 (0)1792 761104 E-mail: medadviser@ dvla.gsi.gov.uk 
plate (post 01 September 2001 font) attached to a motor vehicle. The second of these two prescribed requirements can be checked by all drivers regularly without assistance. Bioptic (telescope) devices are not accepted for driving in Great Britain.

Group 2 entitlement requires, in addition to the above (a) a visual acuity of at least Snellen $6 / 7.5$ in the better eye and (b) a visual acuity of at least Snellen 6/60 in the poorer eye. If correction is needed to achieve this standard it should be with glasses of power no greater than +8 Dioptres in any meridian of either lens, or with contact lenses. The correction must be well tolerated. 'Grandfather rights' for visual acuity apply in certain circumstances depending on the date(s) on which group 2 entitlement may have been held previously.

\section{Visual field standards-group 1 entitlement}

For group 1 driving the width of a horizontal visual field should be at least 120 degrees, with at least 50 degrees on either side of fixation. In addition, there should be no significant defect either within or encroaching into the central 20-degree radius from fixation.

Individuals who do not meet the above visual field standards may be eligible to apply for a licence as an 'exceptional case' if they meet all of a number of strict criteria. Further details are available in the At a glance guide to the current medical standards of fitness to drive. ${ }^{6}$

\section{Visual field standards-group 2 entitlement}

The width of the horizontal visual field should be at least 160 degrees with an extension of at least 70 degrees on either side of fixation, right and left, and 30 degrees up and down. No defect should be present within a radius of 30 degrees from fixation.

\section{Monocularity}

For group 1 entitlement, those with sight in one eye only must meet the same visual acuity and visual field standards as binocular drivers. In addition, there must be evidence of full functional adaptation to monocularity. Monocularity is not acceptable for group 2 driving.

\section{General medical council guidance to doctors}

Although all drivers/applicants have a legal obligation to notify DVLA of any condition that may affect safe driving, there are occasions on which the driver cannot or will not do so. If a patient has a condition that may affect safe driving, the doctor should inform the patient of this and advise that they should notify DVLA immediately. If the patient refuses to accept the diagnosis, or the effect of the condition on safe driving, the doctor may offer a 'second opinion' while advising the patient not to drive in the meantime. If a patient continues to drive against medical advice and/or refuses to notify DVLA of their condition, then the doctor should contact DVLA immediately and disclose any relevant medical information in confidence to the Medical Adviser at DVLA. The doctor should try to inform their patient that they intend to disclose this information to DVLA. Doctors should notify DVLA if disclosure is in the interests of the individual and/or for public safety, that is, if failure to disclose appropriate information would expose the patient or the public to risk of harm or death.

\section{Conflict of interest}

The author declares no conflict of interest.

\section{Further information/references}

1 Panel minutes are available as a PDF on DVLA website: https: / / www.gov.uk/search?q= medical+panels\&tab = government-results.

2 Telephone advice for doctors-01792-782337.

3 E-mail (medical professionals only): medadviser@dvla. gsi.gov.uk.

4 Telephone advice for patients—0300 7906806

5 DVLA website: www.gov.uk/browse/driving.

6 'At a Glance Guide'- available as a PDF on DVLA website: https://www.gov.uk/government/publications/at-a-glance. 